\title{
Identificação e Emergência de Aspectos Relacionados à Cultura Advinda da Utilização de Aparelhos Celulares Inteligentes
}

\section{Identification of Emerging Aspects Related to the Use of Intelligent Mobile Devices}

\section{André Gerstberger ${ }^{a}$; Ieda Maria Giongo ${ }^{a}$}

a Departamento de Ensino de Ciências Exatas, Universidade do Vale do Taquari, Lajeado, Brasil andre_canelavera@hotmail.com, igiongo@univates.br

Palavras-chave:

Etnomatemática.

Smartphone. Ensino de matemática. Ensino

fundamental.
Resumo: O objetivo do presente artigo consiste em compreender de que forma os alunos de uma turma de nono ano do ensino fundamental de uma escola pública, localizada em um município pertencente à Região do Vale do Taquari, RS, utilizam seus smartphones em atividades não escolares. Os aportes teóricos estão em consonância com campo da Etnomatemática, e seus entrecruzamentos com autores que apregoam a utilização das tecnologias digitais em ambientes escolares. A metodologia de pesquisa é de cunho qualitativo com aproximações etnográficas, utilizando a análise descritiva para interpretação dos resultados emergentes. Dentre os resultados emergentes destacam-se: i) portar um celular ultrapassou as barreiras sociais/econômicas; ii) as funções mais utilizadas pelos alunos são a câmera fotográfica e os aplicativos de redes sociais; iii) os celulares inteligentes têm modificado as formas de relação e comunicação.

\begin{abstract}
This study aims understanding how ninth-graders in a public school within the Taquari Valley, RS, Brazil, use their smartphones in non-school activities. The theoretical framework is in consonance with the field of Ethnomathematics and its intertwining with authors who support the use of digital technologies in school environments. The research methodology is qualitative in nature, with ethnographic approaches, with the use of descriptive analysis to interpret the outcomes. The following outcomes have been highlighted: i) owning a cell phone no longer represents a social/economic barrier; ii) the features most commonly used by the students are the camera and the social network applications; iii) smartphones have changed the way people relate to and communicate with each other.
\end{abstract}

\section{Keywords:}

Smartphone. Teaching of mathematics. Primary School. 


\section{Introdução}

Nos últimos anos, em nossa sociedade, tem sido visível a grande aceitação e apropriação da população brasileira quanto à utilização de diversos aparelhos tecnológicos e digitais alcançando as mais diversas faixas etárias. Entretanto, em meio à diversidade dessas ferramentas, uma em especial vem ganhando dos consumidores brasileiros um espaço considerável: o nomeado 'celular'. O fato é que há alguns anos, vem sendo desenvolvido com uma tecnologia de alta qualidade, possuindo um sistema operacional tão eficiente a ponto de caracterizá-lo como um "celular inteligente", motivo pelo qual agora é conhecido tecnicamente como smartphone e iphone.

Considerado por muitos como um elemento indispensável à sobrevivência, sendo, inclusive, comparado a um membro do próprio corpo, o smartphone tem sido um fiel companheiro para todas as horas e momentos de grande parte da sociedade. Consequentemente, sua utilização tem ultrapassado diversas barreiras e alcançado inúmeros ambientes, conquistando cada vez mais a população brasileira, em especial, os adolescentes e jovens.

Diante desse contexto, compreendemos que o nomeado artefato tecnológico - por estar tão presente no cotidiano das pessoas - já faz parte da cultura de nossa sociedade, interferindo diretamente na vida dos indivíduos que o possuem e do próprio meio em que vivem, acarretando novos traços socioculturais. Logo, ao observar tais situações, acreditamos que sua inserção e integração também poderiam ocorrer no interior dos ambientes escolares de forma a valorizar primeiramente aspectos culturais, além de contribuir para os processos de ensino e aprendizagem no âmbito escolar, em especial - neste trabalho - no campo da educação matemática.

Por se tratar de um recorte de uma parte da dissertação (GERSTBERGER, 2016) o foco deste artigo consiste em investigar como tais alunos utilizavam tais aparelhos em ambientes escolares e não escolares. Assim, a referida prática foi desenvolvida pelo primeiro autor deste trabalho em uma escola pública de um pequeno município pertencente à Região do Vale do Taquari, localizado no Estado do Rio Grande do Sul, Brasil. A referida turma era composta por dezessete alunos, sendo seis do sexo feminino e onze do masculino. Ressaltamos que os referidos discentes pertenciam a classes sociais de média, baixa e extrema pobreza, advindos alguns de uma periferia ou "favela" existente no próprio município.

A seguir, fazemos um relato sucinto sobre o campo teórico que sustentou a referida prática pedagógica, bem como seu papel relevante para algumas reflexões e compreensão acerca dos diversos aspectos envolvidos nesta pesquisa. 


\section{O campo da etnomatemática e as tecnologias digitais: algumas possíveis imbricações}

Criado em meados da década de setenta, o termo Etnomatemática foi referenciado pelo professor e pesquisador Ubiratan D’Ambrósio. Em 1984, foi utilizado e oficialmente reconhecido como um campo da educação matemática na quinta edição do ICME (International Congresso on Mathematical Education) (ROSA; OREY, 2006). Segundo D’Ambrósio, para estudar e/ou ensinar a Matemática, é mister analisar o contexto sociocultural em que o aluno está inserido. A partir desse "reconhecimento" e da valorização do ambiente em que o indivíduo se insere, a Matemática se torna contextualizada e concede sentido ao conteúdo estudado, proporcionando ao educando correlacioná-lo com situações de seu cotidiano. Para ele,

A cultura, que é o conjunto de comportamentos compatibilizados e de conhecimentos compartilhados, inclui valores. Numa mesma cultura, os indivíduos dão as mesmas explicações e utilizam os mesmos instrumentos materiais e intelectuais no seu dia a dia. O conjunto desses instrumentos se manifesta nas maneiras, nos modos, nas habilidades, nas artes, nas técnicas, nas ticas de lidar com o ambiente, de entender e explicar fatos e fenômenos, de ensinar e compartilhar tudo isso, que é o matema próprio ao grupo, à comunidade, ao etno. Isto é, na sua etnomatemática (D’AMBRÓSIO, 2013, p. 35-36, grifos dos autores).

Diante disso, ao definir a palavra Etnomatemática em suas raízes da palavra, D’Ambrósio destaca que que sua intenção é valorizar as distintas formas de pensar, agir e saber/fazer na Matemática, pois o principal motivo da Etnomatemática, "é procurar entender o saber/fazer matemático ao longo da história da humanidade, contextualizado em diferentes grupos de interesse, comunidades, povos e nações" (D’AMBRÓSIO, 2013, p. 17). Nesse contexto e corroborando as ideias do mencionado autor, Knijnik et al. (2013) afirmam que "mais do que cultura, a Etnomatemática, assim como a entendemos, está interessada em examinar a diferença cultural no âmbito da Educação Matemática” (KNIJNIK et al., 2013, p. 26).

Em outras palavras, elas defendem que, além dos aspectos culturais, a preocupação está em analisar as diferenças dos existentes nos diversos grupos. Estes estão inseridos em nosso meio e encarados - do ponto de vista da Etnomatemática - como sendo heterogêneos, entendendo ainda que cada indivíduo possui características que também se diferem entre si; logo, sujeito a mudanças. "Para a Etnomatemática, a cultura passa a ser compreendida não como algo pronto, fixo e homogêneo, mas como uma produção, tensa e instável” (KNIJNIK et al., 2013, p. 26). Com esse entendimento, as autoras defendem a ideia de que não existe apenas uma Matemática (a dita Acadêmica), mas múltiplas. Ou seja, declaram que esta - tida por muitos pesquisadores como a única, suficiente e somente praticada por matemáticos também é uma Etnomatemática entre outras manifestações da Matemática. Ao se utilizar de tais ideias, Halmenschlager (2001) defende que 
A perspectiva da Etnomatemática é ampla e, portanto, não se limita a identificar a Matemática criada e praticada por um grupo cultural específico, restringindo-se a essa dimensão local. Considera a matemática acadêmica uma entre outras formas de Etnomatemática. Além disso, os saberes matemáticos dos estudantes, construídos na sua prática cotidiana, no mundo social mais amplo, são também incorporados aos conhecimentos transmitidos pela escola (HALMENSCHLAGER, 2001, p. 27).

Diante disso, procuramos, nesta pesquisa, entrelaçar situações do cotidiano ao currículo escolar, utilizando as tecnologias digitais como ferramentas que auxiliassem, completassem e, se possível, ultrapassassem as barreiras e objetivos propostos e esperados pela ementa da disciplina de Matemática. Assim, reportamo-nos novamente às ideias de D’Ambrósio (2013, p. 66) que, segundo ele, em pleno século XXI, “espera-se que a educação possibilite, ao educando, a aquisição e utilização dos instrumentos comunicativos, analíticos e materiais que serão essenciais para o seu exercício de todos os direitos e deveres intrínsecos à cidadania". Para tanto, o autor define três conceitos, denominados trivium, que acredita serem necessários para alcançar tal objetivo:

LITERACIA: a capacidade de processar informações escrita e falada, o que inclui leitura, escrita, cálculo, diálogo, ecálogo, mídia, internet na vida quotidiana [Instrumentos Comunicativos].

MATERACIA: a capacidade de interpretar e analisar sinais e códigos, de propor e utilizar modelos e simulações na vida cotidiana, de elaborar abstrações sobre representações do real [Instrumentos Analíticos].

TECNORACIA: a capacidade de usar e combinar instrumentos, simples ou complexos, inclusive o próprio corpo, avaliando suas possibilidades e suas limitações e a sua adequação a necessidade e situações diversas [Instrumentos Materiais] (D’AMBRÓSIO, 2013, p. 66-67, grifos dos autores).

Como pesquisadores, acreditamos terem sido tais ideias fundamentais a esta pesquisa, visto que as três 'etapas/conceitos' estabelecidos por D'Ambrósio se complementam, sendo desconsiderada qualquer hipótese de exclusão de algum deles. Assim, buscando compreender um pouco mais de cada fase do trivium proposto pelo pesquisador, fizemos uso dos conceitos de Rosa e Orey (2015), os quais, baseados nos do citado autor, discorrem sobre a referida temática explorando detalhadamente cada um deles .

Ao discursarem sobre a literacia, Rosa e Orey (2015, p. 592, tradução nossa) aludem que esse conceito visa à procura pela identidade sociocultural dos indivíduos envolvidos, que "é melhor compreendida como a integração de contextos escolares e culturais através do processo de dinamismo cultural"1. Assim, objetivando uma melhor explanação do que compreendem acerca da literacia, os autores descrevem que

A literacia é a capacidade de processar informações através da aplicação de técnicas de leitura, escrita, representação e cálculo em uma variedade de contextos diversos de mídia. Podem ser entendidas como as competências relacionadas com o processamento e criação de informação, que incluem habilidades como verificar preços, horários, horários, usar as unidades de medida, realizar operações matemáticas, bem como competências de cálculo como interpretação de gráficos e

\footnotetext{
${ }^{1}$ Original: "is best understood as the integration of school and cultural contexts through the process of cultural dynamism".
} 
tabelas (D'Ambrosio e D'Ambrosio 2013). É um processo que permite aos indivíduos gerenciar com sucesso rotinas diárias e obter acesso a informações ${ }^{2}$ (ROSA ; OREY, 2015, p. 592, tradução nossa).

Para a Etnomatemática, é relevante essa integração e troca de experiências imersas no ambiente de sala de aula. A maneira como os indivíduos buscam informações, pensam e se expressam diante dos demais que os cercam é essencial aos pressupostos do campo da Etnomatemática. É na literacia que podemos explorar as ideias matemáticas e socioculturais de determinados grupos, bem como as práticas a serem desenvolvidas, a fim de contextualizar tais atividades e desenvolver estratégias voltadas ao ensino e à aprendizagem da Matemática (ROSA; OREY, 2015).

Nesse sentido, os autores defendem que o campo da Etnomatemática está fortemente relacionado ao "desenvolvimento das competências, habilidades e habilidades dos alunos através do estudo de ideias, procedimentos e práticas matemáticas diretamente ligadas ao seu próprio contexto sociocultural”3 (ROSA; OREY, 2015, p. 590, tradução nossa). Baseados no pensamento referente à relação intrínseca no campo da Etnomatemática, os autores afirmam que a materacia "permite que os alunos desenvolvam habilidades de raciocínio local, lógico e matemático em uma variedade de ambientes"4 (ROSA; OREY, 2015, p. 590, tradução nossa). Ademais, destacam a necessidade de se estabelecerem relações entre os ambientes escolares e a comunidade, "fazendo conexões diretas entre a matemática da escola acadêmica e as práticas culturais matemáticas desenvolvidas, praticadas e usadas localmente" ${ }^{, 5}$ (ROSA; OREY, 2015, p. 590, tradução nossa).

Ao defender a necessidade de abordar e integrar, dentro do contexto escolar, aspectos relacionados à cultura local e realizar profundas reflexões críticas acerca do papel que a Matemática exerce na sociedade, Rosa e Orey (2015, p. 592, tradução nossa), ancorados nas ideias de D’Ambrósio e D’Ambrósio (2013), asseveram que a

\begin{abstract}
Materacia pode ser entendida como a capacidade de interpretar e gerenciar sinais e códigos, bem como a capacidade de ambos propor e usar modelos na vida cotidiana. Ele ajuda os alunos a desenvolver competências estatísticas que incluem a capacidade de coletar, ler, entender, propor hipóteses, inferir e produzir e interpretar dados para avaliar a sua validade, a fim de tirar conclusões. Materacia fornece aos alunos instrumentos simbólicos e analíticos que os ajudam a desenvolver a sua
\end{abstract}

\footnotetext{
2 Original: "Literacy is the ability to process information by applying techniques of reading, writing, representing, and calculating in a variety of diverse media contexts. It can be understood as the competencies related to the processing and creation of information, which include abilities such as checking prices, times, schedules, using the units of measurement, performing mathematical operations, as well as numeracy competencies such as interpreting graphs and tables (D'Ambrósio and D'Ambrósio 2013). It is a process that allows individuals to successfully manage daily routines and gain access to information."

${ }^{3}$ Original: "development of students' competencies, abilities, and skills through the study of mathematical ideas, procedures, and practices directly connected to their own sociocultural context".

${ }^{4}$ Original: "allows students to develop local, logical, and mathematical reasoning abilities in a variety of environments".

${ }^{5}$ Original: "by making direct connections between academic school mathematics to the mathematical cultural practices developed, practiced, and used locally".
} 
criatividade e a capacitá-los a compreenderem criticamente e a resolver problemas e situações (D'AMBROSIO; D'AMBROSIO, 2013) ${ }^{6}$.

$\mathrm{Na}$ sequência, buscando compreender amplamente o significado daquilo que D’Ambrósio (2013) propõe como tecnoracia, Rosa e Orey (2015) partem do princípio de que, atualmente, o contexto em que vivemos está fortemente entrelaçado com a utilização de ferramentas tecnológicas. Estas devem assumir o papel de auxiliares dos indivíduos em diversas situações do cotidiano e na resolução de novos problemas. Assim, os autores defendem que

Tecnoracia refere-se à capacidade das pessoas de usar criticamente e combinar diferentes ferramentas tecnológicas, desde as mais simples às mais complexas, e sua capacidade de avaliar possibilidades e limitações em diversas situações cotidianas, a fim de tomar decisões adequadas para si e para os outros. Utiliza também as competências em numeracia, como a compreensão da linguagem condensada de códigos e números, através do uso de tecnologia, como calculadoras e computadores (D'Ambrosio 2007) e outros recursos tecnológicos ${ }^{7}$ (ROSA; OREY, 2015, p. 593, tradução nossa).

Nessa perspectiva, os nomeados pesquisadores argumentam que a tecnoracia possui características importantes no contexto etnomatemático no que se refere ao conhecimento científico tanto no mentifacts (valores, princípios, linguagem, valores e pensamentos próprios disseminados dentro de uma sociedade/cultura) quanto nos artefatos (instrumentos, objetos e ferramentas tecnológicas criados por diferentes grupos culturais) (ROSA; OREY, 2015). Corroborando esse pensamento, no livro "Current and Future Perspectives of Ethnomathematics as a Program", Rosa e Orey (2016, p. 22, tradução nossa), ao dissertarem sobre o trivium, afirmam que "tais ambientes facilitam a incorporação de diversos modos de explicação, crença, tradição, mito, e símbolos para o desenvolvimento do conhecimento matemático" $"$.

Diante desse contexto, direcionamos o foco deste trabalho - com base no campo da Etnomatemática - ancorados aos três conceitos: literacia, materacia e tecnoracia. Assim, passamos a analisar a cultura dos jovens e adolescentes inseridos em nossas escolas na tentativa de identificar aspectos culturais que pudessem ser examinados e utilizados na sala de

\footnotetext{
${ }^{6}$ Original: Matheracy can be understood as the capability to interpret and manage signs and codes as well as the ability to both propose and use models in everyday life. It helps students to develop statistical competencies which include the abilities to collect, read, understand, propose hypothesis, infer, and produce and interpret data to assess their validity in order to draw conclusions. Matheracy provides students with symbolic and analytical instruments that help them to develop their creativity and enable them to critically understand and solve problems and situations (D'Amboise and D'Amboise 2013).

Original: "Technoracy refers to people's ability to critically use and combine different technological tools, from the simplest to the most complex, and their ability to evaluate possibilities and limitations in diverse everyday situations in order to make suitable decisions for themselves and for others. It also makes use of numeracy competencies, such as the understanding of the condensed language of codes and numbers, through the use of technology, such as calculators and computers (D'AMBROSIO, 2007) and other technological resources".

${ }^{8}$ Original: "Such environments facilitate the incorporation of diverse modes of explanation, belief, tradition, myth, and symbols in the development of mathematical knowledge".
} 
aula. Nesse sentido, podemos identificar que um dos aspectos culturais presentes na cultura de nossa sociedade está relacionado à aquisição e utilização constante de smartphones. Esse aparelho tem sido utilizado nos mais diversos espaços, desde lanchonetes, restaurantes, filas de banco, supermercados, lojas, aeroportos, igrejas, até nos mais perigosos, como o trânsito.

Mesmo os smartphones sendo utilizados praticamente em todos os espaços, um ambiente que se tem colocado contrário ao seu uso é a escola. Diante dessa situação, Borba et al. (2014) aludem que ela tem criado barreiras e preferido proibir o uso dos celulares em seu ambiente ao invés de buscar estratégias que contribuam para os processos de ensino e aprendizagem. Segundo os autores,

As tecnologias digitais móveis - internet, celular, tablets - estão modificando as normas que vivemos, os valores associados a determinadas ações. Mais uma vez isso acontece em ritmo diferente fora e dentro da escola. Assim o abismo entre práticas que alunos e professores têm fora da escola e dentro da mesma instituição aumenta (BORBA et al., 2014, p. 42).

A utilização de tecnologias móveis, como laptops, telefones celulares ou tablets, tem se popularizado consideravelmente nos últimos anos em todos os setores da sociedade. Muitos de nossos estudantes vêm usando a internet em sala de aula a partir de seus telefones para acessar plataformas, como o Google, bem como as câmeras fotográficas ou de vídeo para registrar momentos das aulas. Estas já estão sendo moldadas por essas ferramentas, criando novas dinâmicas, transformando a inteligência coletiva, as relações de poder (da Matemática) e as normas a serem seguidas nessa mesma sala de aula (BORBA et al., 2014, p. 77).

Hoje, tais aparelhos, denominados 'celulares inteligentes' (em razão da existência de um sistema operacional inteligente - iOS ou Android, que permite comandos por meio de toques em tela, movimentos oculares e/ou sensores, presença, (re)produzindo uma espécie de inteligência artificial) possuem inúmeras funções, e várias são as maneiras de utilizá-los, totalmente inimagináveis no início da invenção do telefone fixo. Para Borba et al. (2014, p. 80), "há uma 'cultura do celular' sendo desenvolvida que privilegia interações sociais via essa mídia como meio de contato social".

De fato, portá-lo, para muitos, virou item de necessidade básica tanto para a sobrevivência (trabalho, recados, avisos) como para o lazer (comunicação rápida, troca de informações, redes sociais, diversão, entre outros). Para a pesquisadora Kenski (2014), as tecnologias digitais não modificam apenas o sujeito momentaneamente, mas também a nossa cultura.

Nessa perspectiva, várias têm sido as utilidades do aparelho celular, que, por meio de aplicativos, poderia servir também como ferramenta que potencializa as práticas de ensino, em especial, o da Matemática (BORBA et al., 2014). Segundo os autores,

Partindo do princípio de que os celulares hoje são um bem de consumo democrático, no sentido de que praticamente todos os alunos os têm (embora ainda persista a 
desigualdade entre os celulares disponíveis) cremos que se os celulares passarem a contar com aplicativos que emulem uma calculadora gráfica, as escolas poderiam ter sensores e a ideia de uma sala de aula de Matemática com movimento corporal intenso poderia voltar a fazer parte do imaginário dos educadores matemáticos (BORBA et al., 2014, p. 80).

Nesse sentido, entendemos que nossos alunos estão vivendo em um momento cultural diferente e - como docentes - precisamos buscar estratégias de ensino que atendam a esse novo público escolar. Para Halmenschlager (2001, p. 15),

Hoje, outros são os enfoques que vêm sendo dados à Educação Matemática, agora não só atenta à importância do conhecimento matemático como ferramenta na solução de problemas imediatos que possam ajudar as pessoas nas suas atividades diárias, como também preocupada com sua contribuição para a compreensão do mundo mais amplo em que vivem. Entre esses enfoques, situa-se a Etnomatemática, que se apresenta como uma perspectiva do currículo porque é uma abordagem fundada nas conexões entre a cultura dos alunos e das alunas e o conhecimento escolar.

Sendo assim, pensamos ter sido válida a proposta de utilizar as tecnologias, em especial o aparelho celular, na sala de aula, dentro da perspectiva Etnomatemática. Segundo D’Ambrósio (2013, p. 46-47),

A proposta pedagógica da etnomatemática é fazer da matemática algo vivo, lidando com situações reais no tempo [agora] e no espaço [aqui]. E, através da crítica, questionar o aqui e agora. Ao fazer isso, mergulhamos nas raízes culturais e praticamos dinâmica cultural. Estamos, efetivamente, reconhecendo na educação a importância das várias culturas e tradições na formação de uma civilização, transcultural e transdisciplinar.

Posto isso e com base nos escritos deste referencial teórico, descrevemos, detalhadamente, na próxima seção, os caminhos percorridos durante a intervenção desta proposta, com as práticas pedagógicas desenvolvidas, visando alcançar os objetivos propostos.

\section{Metodologia}

Preocupados com questões científicas e culturais relacionadas ao campo da Etnomatemática e desempenhando, simultaneamente, o papel de professores e de pesquisadores, exploramos diversos aspectos relacionados ao ensino da Matemática e seus entrecruzamentos com a utilização e integração dos smartphones emergentes da cultura dos alunos. Com o propósito de valorizar aspectos socioculturais engendrados nos investigados, procuramos atraí-los à investigação, tornando-os protagonistas.

Assim, alicerçamos esta pesquisa numa metodologia qualitativa, visto que ela se preocupa em "analisar e interpretar aspectos mais profundos, descrevendo a complexidade do comportamento humano. Fornece uma análise mais detalhada sobre as investigações, hábitos, atitudes e tendências de comportamento" (LAKATOS; MARCONI, 2004. p. 269). Já para Godoy (1995, p. 62), “a pesquisa qualitativa tem o ambiente natural como fonte direta de 
dados e o pesquisador como instrumento fundamental". Diante desse entendimento, a autora defende que

\begin{abstract}
Os estudos denominados qualitativos, têm como preocupação fundamental o estudo e a análise do mundo empírico em seu ambiente natural. Nessa abordagem valorizase o contato direto e prolongado do pesquisador com o ambiente e a situação que está sendo estudada. [...] Para esses pesquisadores, um fenômeno pode ser mais bem observado e compreendido no contexto em que ocorre e do qual é parte. Aqui o pesquisador deve aprender a usar sua própria pessoa como o instrumento mais confiável de observação, seleção, análise e interpretação dos dados coletados (GODOY, 1995, p. 62).
\end{abstract}

Sendo assim, direcionamo-nos à presente pesquisa de cunho qualitativo e de inspirações etnográficas, que vem trazendo e produzindo significativos, principalmente no campo da Etnomatemática, verificados nas pesquisas de Picoli (2010), Grasseli (2012) e Zanon (2013). Segundo D’Ambrósio (2012), o mais importante e essencial nesse tipo de pesquisa é manter o foco no indivíduo a ser investigado:

\begin{abstract}
A pesquisa qualitativa é muitas vezes chamada de etnográfica, ou participante, ou inquisitiva, ou naturalista. Em todas essas nomenclaturas, o essencial é o mesmo: a pesquisa é focalizada no indivíduo, com toda a sua complexidade, e na sua inserção e interação com o ambiente sociocultural e natural. O referencial teórico, que resulta de uma filosofia do pesquisador, é intrínseco ao processo. Naturalmente a interação pesquisador-pesquisado é fundamental e por isso essa modalidade é muitas vezes chamada pesquisação. Não é surpreendente o fato de essa modalidade de pesquisa ser típica dos antropólogos (D’AMBRÓSIO, 2012, p. 93).
\end{abstract}

Nesse sentido, D’Ambrósio (2012) sustenta que, numa pesquisa com tal enfoque, é fundamental que haja uma interação entre o pesquisador e o pesquisado durante os processos investigativos. Ainda sobre a pesquisa etnográfica, o autor afirma que "desde que a questão envolva seres humanos, são essenciais a descrição e a reconstrução de cenários culturais, o que é normalmente chamado uma etnografia” (D’AMBRÓSIO, 2012, p. 93-94).

Diante desse contexto, reportamo-nos às ideias de Godoy (1995, p. 63), que asseguram que "os pesquisadores qualitativos estão preocupados com processo e não simplesmente com os resultados do produto". Para tanto, a autora defende que, para a pesquisa qualitativa, uma análise de dados eficaz é a descritiva, alegando que "quando o estudo é de caráter descritivo, o que se busca é o entendimento do fenômeno como um todo, na sua complexidade" (GODOY, 1995, p. 63). Por sua vez, Gil (2202) argumenta que algumas características das pesquisas descritivas são a exploração e análise de diversos contextos culturais e grupos específicos, "levantar as opiniões, atitudes e crenças de uma população" (GIL, 2002, p. 42).

A referida investigação foi realizada nos meses de outubro a dezembro de 2015 , em uma turma de Nono Ano do Ensino Fundamental de uma escola pública, situada em um pequeno município da Região do Vale do Taquari, Rio Grande do Sul. A escolha da turma ocorreu em conjunto com o grupo de pesquisa ao qual a investigação estava vinculada, sendo que este era também composto por seis professores de Matemática de diferentes escolas da região. Uma destas foi a selecionada para lócus da pesquisa tendo em vista a solicitação de 
sua docente representante, professora titular da disciplina. Pontuamos ainda que a turma escolhida se deu em consonância com a escola, a qual ofertava apenas uma de cada 'ano' do Ensino Fundamental

Assim, realizamos um período de observação - uma semana - com o intuito de buscar um primeiro contato com os alunos a serem investigados. Ademais, durante a investigação, a professora regente de Matemática acompanhou o desenvolvimento de todas as atividades propostas, que teve carga horária de vinte e seis horas-aulas. Os encontros ocorreram durante os períodos das aulas da própria disciplina, em apenas dois dias da semana, sendo que os demais estavam a cargo da docente titular para dar sequência ao seu planejamento de ensino.

Em seguida, expomos e analisamos alguns resultados emergentes da investigação.

\section{Resultados}

Tais tecnologias têm contribuído para uma potencial melhora na qualidade de vida das pessoas, propiciando, por exemplo, o aumento da expectativa de vida, o diagnóstico precoce de doenças, a descoberta de medicamentos mais eficientes que possam minorar o sofrimento humano. Mas são essas mesmas tecnologias que também têm intensificado a distância entre os que têm acesso e esses progressos científicos e os que deles estão cada vez mais afastados (KNIJNIK et al. 2013, p. 82).

No excerto, as pesquisadoras Knijnik et al. (2013) expõem algumas reflexões acerca da necessidade e importância de incorporar novas ferramentas no ensino. Contudo, evidenciam suas preocupações quanto aos problemas que elas podem causar. Ancorados nessas indagações, iniciamos esta unidade de análise com o intuito de abordar aspectos que emergiram durante a efetivação da prática pedagógica. Portanto, é nossa pretensão, nesta seção, compreender minuciosamente como os alunos utilizavam seus smartphones em atividades escolares e não escolares.

Um de nossos primeiros questionamentos - e também curiosidades - efetivados no início foi conhecer o quantitativo de alunos da turma investigada que possuía um aparelho celular digital smartphone e/ou iphone. A pergunta era crucial tanto para a pesquisa quanto para o início das discussões que estavam por vir. Para nossa surpresa, todos responderam que dispunham da ferramenta em questão.

Nesse momento, uma de nossas crenças se desconstruiu, motivo pelo qual fomos tomados pelo espanto. Como justificativa para tal sentimento, citamos que, por se tratar de uma escola pública, localizada em um pequeno município do interior do Estado e, consequentemente, com estudantes de diferentes classes sociais, (média, baixa e extrema pobreza), compreendemos que portar um aparelho celular ultrapassara as barreiras sociais e 
econômicas na referida localidade, ou seja, tê-lo não mais se restringia a um grupo específico de pessoas, algo que não havíamos assimilado até então 9 .

Ao constatar tal fato, indagamos aos alunos o que pensavam sobre essa ferramenta. Segundo um deles ${ }^{10}$,

Aluno H: Hoje em dia, é uma ferramenta de trabalho muito, muito... utilizada e eficaz!

Professor: Por que você acha que o celular é uma ferramenta eficaz e muito utilizada para o trabalho?

Aluno H: Ela dá muita facilidade ao trabalho, dependendo de como você trabalha, permite pesquisar...

O relato desse aluno levou-nos a questionar o papel que o citado artefato exercia no cotidiano desses adolescentes. Assim, perguntamos qual era a função principal, para eles, dos smartphones.

\author{
Aluno N: Rede Social \\ Aluno O: Rede Social \\ Aluno K: Rede Social \\ Aluno E: Ver hora e Ouvir Música \\ Aluno M: Rede Social \\ Aluno C: Rede Social \\ Aluno D: Rede Social \\ Aluno G: Games e Rede Social \\ Aluno I: Rede Social \\ Aluno B: Rede Social \\ Aluno P: Vídeo \\ Aluno A: Rede Social \\ Aluno J: Rede Social \\ Aluno Q: Rede Social \\ Aluno H: Rede Social
}

Professor: O que vocês mais gostam de mexer?

As enunciações dos entrevistados confirmam que as redes sociais os atraíam e instigavam a utilizarem constantemente seus smartphones. De modo análogo, porém não com igual representação numérica, a pesquisa de Moreira e Santos (2016), realizada com um grupo de alunos da Educação de Jovens e Adultos (EJA), em Lisboa, demonstra que a realidade tem sido a mesma em Portugal. Segundo as autoras, graças à facilidade proporcionada pelas tecnologias móveis, a maioria dos discentes utilizava a internet para acessar as redes sociais.

Ao constatar a familiaridade da turma com o smartphone e com o intuito de com ela estreitar os laços, propomos a criação de um grupo no WhatsApp por meio do qual nos relacionaríamos virtualmente fora do espaço escolar. A intenção era facilitar o acesso e a comunicação aluno/aluno e professor/pesquisador/aluno. Entretanto, estabelecemos algumas 'normas de convívio/conduta' que seriam adotadas pelo grupo, tais como: respeito,

\footnotetext{
${ }^{9}$ O contexto a que nos referimos se restringe ao Brasil, desconhecendo (e não emitindo juízo de valor) a realidade de outros países.

${ }^{10}$ Os nomes dos alunos foram substituídos por letras buscando preservar-lhes a identidade, bem como manter a ética nesta pesquisa.
} 
companheirismo, liberdade de expressão e questionamentos. As duas últimas seriam realizadas com responsabilidade e bom senso.

Kenski (2014), ao abordar questões relacionadas à utilização das novas mídias, prega os diversos benefícios, citando que "as facilidades de interação e comunicação oferecidas pela web redefiniram estratégias e procedimentos para o oferecimento de processos de capacitação dinâmicos, de acordo com as necessidades e os interesses dos participantes" (KENSKI, 2014, p. 60). Assim, a autora reconhece que a "intercomunicação é um dos pontos mais significativos dessas novas mídias”. Segundo ela, independentemente de onde as pessoas estejam, elas podem [...] "se comunicar, trocar ideias, desenvolver projetos em conjunto, ir além da informação" (KENSKI, 2014, p. 67). A citada pesquisadora sustenta sua ideia afirmando que

A tecnologia, em sua versão mais avançada, altera a relação temporal e redefine os espaços de atuação profissional. O professor passa a atuar em qualquer lugar, desde que esteja conectado e interagindo com o trabalho. Essa relação professor-trabalho, mediada pelas tecnologias, avança pelos seus tempos diários, outrora "livres", e alcança os finais de semana e mesmo as férias (KENSKI, 2014, p. 59-60).

Ancorados nessas ideias e após estabelecer com os alunos as normas de convivência/ conduta para a comunicação virtual, decidimos questioná-los sobre os benefícios e malefícios referentes ao uso do smartphone. Além de suas opiniões, também tencionávamos averiguar os argumentos que eles utilizariam para defender seus pontos de vista.

\footnotetext{
Professor: Quero que vocês comentem um pouco sobre os benefícios e malefícios.

Aluno J: Comunicação.

Professor: O que mais?

Aluno H: Não só o celular, como o computador, facilita muito, deixam uma mobilização fácil. Antes demorava meses e anos pras pessoas se reunir e fazer uma mobilização. Hoje em dia, em poucos dias ou semanas, você consegue reunir as pessoas pra fazer uma mobilização ou protesto.

Professor: O que mais o celular traz de benefício além da comunicação?

Aluno I: Aprendizado!

Professor: Por que aprendizado? Em quê?

Aluno H: Você pode aprender o que tu quiser e quando tu quiser, na hora que você quiser conectado na internet.
}

As declarações acima evidenciam que os respondentes apontaram somente os benefícios. Ademais, a fragilidade dos argumentos impedia que se fomentassem discussões e relatos. Cientes disso, entregamos uma reportagem da Revista Veja que fazia algumas indagações sobre situações do dia a dia, inclusive com algumas imagens relacionadas ao uso constante/excessivo de aparelhos celulares. Solicitamos que formassem grupos de dois ou três integrantes e, posteriormente, lessem a reportagem e analisassem as referidas imagens. Nesse seguimento, as duplas e/ou trios socializaram com os demais colegas, momento em que discutiram e expuseram suas opiniões.

Professor: Pessoal, quem quer começar a falar sobre a reportagem?

Aluno J: Eles estão perto e ao mesmo estão longe um do outro.

Aluno E: Três amigas que não estão nem aí umas pras outras... 
Aluno G: Eu já passei por isso com minhas amigas... tipo uma vez quando saí com minhas amigas, e elas ficaram só mexendo no celular, e eu fiquei sem conversar.

Aluno M: Eu fazia isso com a minha mãe, eu ficava jogando e ela ficava me chamando. Aí eu digo: Ah! para mãe! Mas aí ela sempre briga, e tenho que parar de jogar pra falar com ela.

Professor: Em que lugar elas estão?

Aluno O: Essa aqui elas estão em uma lanchonete ou restaurante...

Alunos: É...

Professor: O lugar aparenta ser bacana? Gostoso de se estar?

Aluno J: Pelo jeito, sim...

Aluno A: A gente fala que não, mas é assim, isso é quase que automático. Porque a gente sai pra lanchonete e a primeira coisa pede a senha do Wi-Fi...

Aluno H: Aí acaba que a gente fica mais no celular do que interagindo entre nós mesmos...

Professor: As Lanchonetes que vocês frequentam costumam oferecer Wi-Fi para os clientes?

Aluno I: Aqui quase todas as lanchonetes têm Wi-Fi.

Aluno Q: Eu peço primeiro a senha do Wi-Fi, depois peço o cardápio.

Alguns alunos: Eu também.

Aluno G: Eu primeiro peço o cardápio e depois a senha do Wi-Fi.

Aluno K: Eu e meus amigos, e até quando saio com a família, já escolhemos o lugar sabendo que a Wi-Fi é boa e vai funcionar. A gente tenta não ficar muito, mas não dá pra ficar sem internet!

Professor: Vocês concordam com o colega?

Aluno J: Claro professor, imagina ir e não poder acessar a internet, mandar uma foto pros amigos, fazer check-in no facebook...

Professor: Mas e se não tiver Wi-Fi? Aí não vai?

Aluno M: Não, eu não.

Aluno G: Ah, depende, mas talvez não.

Aluno K: Só se a comida for, tipo assim, MUITO BOA.

Aluno N: Ah, sei lá, é difícil, o bom seria ter os dois [risos].

Professor: Então, dependendo de como for, se não tiver Wi-Fi, vocês não vão à lanchonete ou restaurante?

Aluno D: Sim.

Professor: Entendi...

Aluno I: O interessante é que tá tudo mundo junto como amigo, só que leva o celular com internet junto e, ao invés de conversar normal igual à gente tá agora, pessoalmente, conversa por rede social.

Aluno G: Mas ssor ${ }^{11}$, pro senhor ter ideia de como a gente gosta de Wi-Fi, quando a gente vai juntar pra fazer trabalho, a gente escolhe a casa de quem tem Wi-Fi...

Professor: Como é?

Aluno M: É ssor, tipo, quando os outros professores pedem pra fazer trabalho em grupo, tipo fora da escola, a gente só faz na casa de quem tem a Wi-Fi.

Aluno J: E a gente vê sempre na casa de quem a internet é melhor.

Aluno A: Pra pesquisar ou olhar algum vídeo sobre o conteúdo do trabalho... às vezes a gente só tem um computador e aí, quando precisamos pesquisar mais coisas, usamos o celular pra agilizar e ajudar a fazer o trabalho.

Aluno M: É, porque tipo, e a gente sempre fica na net depois.

Professor: Então, vocês gostam de realizar trabalhos na casa de quem tem internet Wi-Fi?

Aluno G: E muitooo!

Professor: E quem não tem Wi-Fi em casa?

Aluno M: Aí vamos na casa de outro!

Professor: Quantos aqui têm internet Wi-Fi em casa? Levanta a mão.

[...]

Professor: Só dois aqui na sala não tem Wi-Fi em casa...

Aluno I: Mas é porque toda família mexe... Minha mãe, quando mexe no celular, é pior que gente, ela esquece de todos.

Aluno G: A minha avó tem setenta anos e ela adora mexer no celular

\footnotetext{
${ }^{11}$ Abreviatura utilizada pelos alunos para se referirem ao professor.
} 
Os relatos acima confirmam que o principal motivo que levava os alunos a utilizarem com tamanha frequência os smartphones era a interação por meio das redes sociais proporcionada pela conexão da internet móvel, em especial a Wi-Fi. Logo, esta tem sido a causa maior da aquisição e crescimento desenfreado da citada ferramenta. Além disso, ficaram perceptíveis a dependência e a necessidade dos discentes de estarem conectados a uma rede, tornando-se, inclusive, relevante a escolha de um local de lazer com amigos e familiares com oferta de Wi-Fi.

Esse fato corrobora a pesquisa de Gerstberger et al. (2016) desenvolvida com alunos do Ensino Médio de uma escola localizada no Norte do Estado de Mato Grosso. Segundo a turma investigada, a oferta gratuita da internet era o diferencial no ramo gastronômico, um serviço que, às vezes, os clientes concediam uma importância maior que ao próprio paladar.

\begin{abstract}
Outra curiosidade que surgiu nesse momento foi que, segundo eles, quando resolvem sair para alguma lanchonete ou restaurante da cidade com seus amigos, procuram primeiramente verificar se o local possui o serviço de internet Wi-Fi gratuito para clientes, e afirmaram que muitas vezes deixaram de frequentar determinadas lanchonetes ou trocam de restaurante por não oferecer esse serviço gratuitamente aos seus clientes (GERSTBERGER, et al., 2016, p. 177).
\end{abstract}

Ao reiterar as declarações dos alunos com quem desenvolvemos a pesquisa, percebemos a influência exercida pela internet na vida escolar da turma. Segundo eles, quando se reuniam em grupos para realizar trabalhos fora da escola, optavam pela residência de um colega onde a internet funcionava de maneira 'mais eficaz', justificando, assim, sua importância e utilização no desempenho das atividades. Nesse sentido, Moreira e Santos (2016) aludem que o maior acesso à internet decorre da crescente aquisição e facilidade que os telemóveis ${ }^{12}$ proporcionam:

[...] destacamos que o acesso à Internet é largamente estabelecido a partir dos telemóveis. A divulgação das tecnologias móveis tem permitido que a aquisição, sobretudo de telemóveis seja fácil para os jovens, o que juntamente com que a possibilidade de acesso à rede, tem transformado os processos de aprendizagem e as práticas culturais da geração net (MOREIRA ; SANTOS, 2016, p. 20-21).

Logo, para os alunos, acessar a internet era uma ação corriqueira e, conforme Moreira e Santos (2016), tem modificado fortemente as práticas culturais da denominada "geração net". Cumpre lembrar que, diante disso, nossa curiosidade enquanto pesquisadores aumentou consideravelmente, fazendo com que buscássemos a maior quantidade possível de informações sobre o mundo e a realidade que cercava os nossos pesquisados. Diante disso, decidimos questioná-los há quanto tempo utilizavam essa ferramenta tecnológica.

Professor: Com quantos anos vocês começaram a mexer com celular? Ou tiveram seu primeiro aparelho?

Aluno K: Eu tinha sete anos.

Aluno O: Eu também, desde uns sete, oito anos de idade.

Aluno H: É nessa média.

\footnotetext{
${ }^{12}$ Termo normalmente utilizado em Portugal para se referir aos aparelhos celulares.
} 
Aluno J: Desde os seis.

Aluno M: Oito anos.

Aluno G: Desde os dez.

Aluno N: É por aí, ssor.

Essas afirmações nos levaram à constatação de que os celulares haviam conquistado o público fazia muito tempo. Considerando que a média de idade dos alunos era de quatorze a quinze anos e que a maioria deles já possuía aparelhos celulares havia quatro a cinco anos , comprova que esse artefato tecnológico se fazia presente em, pelo menos, um terço da vida desses indivíduos. O fato nos reportou a D’Ambrósio (2016) quando relata que a Matemática vai muito além do que se entende por etno, pois é uma construção pessoal, etimológica e histórica.

Eu percebi que o etno prefixo é muito mais amplo que étnica. Isso significa um conhecimento culturalmente identificado grupo de compartilhamento e práticas, linguagem e mitos. Na verdade, o que muitas etnomatemáticas estão fazendo é procurando étnico-matemática, que é contraditória. A natureza, história e filosofia da matemática têm mostrado como inadequado é olhar para a matemática em diferentes grupos étnicos, bem como em diferentes etnias ou culturas ${ }^{13}$ (D’AMBRÓSIO, 2016, p. 7, tradução nossa).

Compartilhar tais ideias foi nossa concepção durante o desenvolvimento desta pesquisa, em especial no campo da Etnomatemática. Ao 'imergirmos' no contexto cultural dos alunos, ampliamos nossa visão quanto à realidade e ao que o termo etno poderia significar para um pesquisador etnomatemático. Assim como para D’Ambrósio, não é nossa intenção apenas procurar culturas distintas e verificar a matemática que possivelmente venha a emergir, mas reconhecer e tentar compreender o que isso representava para os indivíduos pertencentes ao citado grupo cultural, valorizando a influência e a importância das ações usualmente desenvolvidas.

Cabe ressaltar que o assunto redes sociais, em especial o Facebook, novamente fez parte do diálogo que estabelecemos com a turma. A declaração da Aluna J Sem a câmera [do smartphone] não tem graça demonstra uma das maneiras por meio da qual esse público costumava se comunicar, ou seja, pelas imagens.

Professor: Por que tu disseste que sem a câmera não teria graça?

Aluno I: Na verdade, sem a câmera e sem a internet né? [...] porque o que geralmente a gente mais gosta é de tirar foto, ou fazer vídeo.

Aluno Q: Porque a foto virou um jeito de comunicação...

Professor: Como assim?

Aluno K: É, a imagem mostra onde estamos e o que estamos fazendo!

Professor: Vocês gostam de tirar foto?

Alunos: Simmm!

Professor: Por que vocês gostam de postar foto?

Aluno M: Pra se mostrar.

\footnotetext{
${ }^{13}$ Original: "I realized that the prefix ethno- is much broader that ethnic. It means a culturally identified group sharing knowledge and practices, language, and myths. Indeed, what many ethnomathematicians are doing is looking for ethnic-mathematics, which is contradictory. The nature, history, and philosophy of mathematics have shown how inappropriate it is to look for mathematics in different ethnic groups, as well as in different ethnos or cultures".
} 
Aluno B: Pra todo mundo ver que tu foi num lugar diferente e que tu gostou.

Professor: Mas lugares comuns? Por exemplo, alguém aqui posta foto que está indo pra escola? Tipo \#PartiuEscola?

Aluno E: Tem gente aqui na sala que já fez isso...

Aluno B: Ah, no início do ano quando é novidade sim, é comum ver, mas depois que já vira comum ninguém posta mais...

Professor: Por quê?

Aluno B: Porque não, é mais comum!

Aluno H: A gente gosta de postar coisas que são diferentes e que geralmente não fazemos. E mostrar pra galera que isso é legal.

Os enunciados acima atestam a necessidade de os adolescentes mostrarem que pertenciam à sua 'rede' de amizades e o quanto lhes aprazia postar situações incomuns que ocorriam no cotidiano. A declaração $\{. .$.$\} a foto virou um jeito de comunicação modificou$ nossa maneira de pensar as postagens nas redes sociais. Os pesquisados não faziam uso apenas de recursos escritos, como mensagem de texto via SMS ou WhatsApp, tampouco da própria ligação do aparelho móvel, que era sua utilidade ao ser inventado. Por outro lado, as imagens de fotografia, mais comuns em selfies (autorretrato), representavam uma forma de comunicação para eles. Assim, talvez, o famoso ditado popular "uma imagem vale mais que mil palavras"14, criado pelo filósofo chinês Chiu Kung (mais conhecido como Cafúncio), seja adequado para caracterizar esse momento, principalmente em relação às redes sociais, haja vista a ampla comunicação por meio de imagens. Essa constatação fazia parte da 'etno' do grupo de estudantes, podendo ser compreendida como um conceito fortemente influenciável na cultura do smartphone. Ademais, a afirmação Sem câmera e sem internet não tem graça exemplifica os principais motivos de essa ferramenta ter se tornado tão atrativa. Nesse sentido, Borba (2012) ressalta a importância de se inserir a internet no contexto escolar/educacional, justificando ser esta um anseio da sociedade da qual fazem parte alunos e professores. Em efeito,

[...] será necessário encontrar um lugar para a internet em nossas tarefas educacionais se queremos problemas a ser de interesse para os muitos estudantes e professores que consideram a internet uma necessidade básica. Fazer um problema 'interessante' para muitos estudantes pode significar que permite a utilização da internet como parte do coletivo que vai resolver o problema, em conjunto com outras tecnologias, incluindo tradicional em papel e lápis. A tecnologia digital não é uma maneira de melhorar o ensino, embora possa fazê-lo, mas é necessário incorporá-lo em nossas práticas, porque é parte do desejo humano, das possibilidades humanas, ou porque o ser humano de hoje, para uma parte significativa da população do mundo, significa ser humano com a tecnologia digital (Norman 2004) ${ }^{15}$ (BORBA, 2012, p. 805, tradução e grifos nossos).

\footnotetext{
${ }^{14}$ Extraído de https://www.significados.com.br/uma-imagem-vale-mais-que-mil-palavras/. Último acesso em 28 de fevereiro de 2017.

${ }^{15}$ Original: "it will be necessary to find a place for the internet in our educational tasks if we want problems to be of interest for the many students and teachers who consider the internet a basic necessity. Making a problem "interesting" for many students may mean allowing the use of the internet as part of the collective that will solve the problem, together with other technologies, including traditional paper and pencil. Digital technology is not a way of improving teaching, although it may do so, but it is necessary to incorporate it into our practices because it is part of human desire, of human possibilities, or because being human today, for a significant proportion of the world's population, means being human with digital technology (Norman 2004)".
} 
Portanto, é inquestionável a importância da internet na aquisição e utilização acelerada dos smartphones, e a sua câmera como a 'função' que dá grande suporte à maioria dos interesses de seus usuários. Tais elementos caracterizam, e de certa forma justificam, aspectos que são cruciais à 'cultura do smartphone'. Posto isso e ancorados nas ideias de Rosa e Shirley (2016), podemos afirmar que o campo da etno

[...] nos fornece um paradigma de pesquisa que é muito mais ampla do que os conceitos tradicionais de matemática, etnia e multiculturalismo, onde etno está relacionado com grupos distintos identificados por tradições culturais, códigos, símbolos, mitos e formas específicas de raciocínio e inferência ${ }^{16}$ (ROSA; SHIRLEY, 2016, p. 2, tradução nossa).

O pensamento de Rosa e Shirley nos autoriza a caracterizar os elementos identificados (internet e câmera/imagem) como sendo uma espécie de simbologia e/ou códigos advindos da cultura de nossos pesquisados. Diante disso, outra atividade que julgamos necessário abordar emergiu de uma apresentação de trabalho proposta ao longo das práticas pedagógicas. Instigados a verificarem como as pessoas se relacionavam e utilizavam seus celulares, os alunos decidiram investigar questionando estudantes de outras turmas da própria escola.

É importante destacar que essa atitude nos surpreendeu. A empolgação dos estudantes ao 'assumirem' o papel de pequenos pesquisadores/investigadores era evidente, deixando-nos extremamente perplexos. Nesse momento, nossa incumbência se resumia em ouvi-los e apoiálos nessa iniciativa de buscar respostas mais aprofundadas quanto à temática. De acordo com D’Ambrósio (1986), o professor, ao trabalhar em sala de aula, necessita estar ancorado no campo da Etnomatemática.

Naturalmente, ao se considerar de forma integrada conteúdos, objetivos e métodos, considerações de natureza sociocultural estarão permanentemente em jogo. É aí que é fundamental a capacidade do professor de reconhecer no aluno um determinante na definição dos objetivos daquela prática pedagógica. Em termos bem simples, o professor deve ouvir mais, o aluno tem muito a dizer sobre suas expectativas, que no fundo refletem as expectativas de seus pais. Embora haja dificuldade do aluno em se expressar com relação a essas expectativas, cabe ao professor reconhecer aí os grandes motivadores da presença do aluno na escola (D’AMBRÓSIO, 1986, p. 46).

Ao constatar a motivação da turma causada pelo tema proposto, decidimos aceitar e colocar em prática suas ideias. O primeiro passo foi a reconstrução do questionário anteriormente elaborado pelo grupo e exposto na Figura 1.

\footnotetext{
${ }^{16}$ Original: "It provides us with a research paradigm that is much wider than the traditional concepts of mathematics, ethnicity, and multiculturalism, where ethno is related to distinct groups identified by cultural traditions, codes, symbols, myths, and specific ways of reasoning and inferring”.
} 


Amamos Matemática T....
Este é um questionário de pesquisa

Figura 1 - Questionário elaborado e enviado via whatsapp

Fonte: Material produzido pelos alunos

Finda a elaboração do questionário, visitamos as demais turmas da escola para divulgar a pesquisa e encontrar interessados em responder a tais indagações. Das seis séries consultadas, aproximadamente, cinquenta alunos disponibilizaram seus contatos para posterior envio dos arquivos; contudo, apenas vinte e seis foram devolvidos.

Indagados sobre a quantidade de arquivos respondidos, os alunos declararam que, possivelmente, alguns haviam disponibilizado seus contatos movidos apenas pela curiosidade em saber o que estava sendo perguntado, pois, com frequência, eram questionados por esses colegas sobre a proposta que estava sendo desenvolvida. Já outros desejavam preservar a privacidade, pois, segundo eles, a gente não sai passando o número do celular pra qualquer um [pessoas desconhecidas].

Dessa forma, os questionários foram enviados por meio da internet móvel de seus dispositivos ou pela própria internet $W i-F i$ das casas dos alunos. Embora a escola tivesse uma postura 'liberal' acerca da concessão de internet Wi-Fi para os estudantes, em grande parte do ambiente escolar, era bloqueada, impedindo, assim, que fosse utilizada em aplicativos e sites. Contudo, diversos pesquisadores têm apontado as redes sociais, entre elas, o Facebook, como instrumentos que auxiliam no ensino, em especial da Matemática, tais como Borba et al., 
(2011), Peruchin e Nardini (2016), Idris e Wang (2009). Ao refletirem sobre a pesquisa realizada por Borba et al., (2011) e Borba et al. (2014, p. 89) criticam as escolas por não permitirem que essas ferramentas façam parte dos processos de ensino, pois

As pessoas têm utilizado os celulares com estudantes, com namorados, e com filhos. Elas utilizam o Facebook em suas relações pessoais e também em pequenos negócios. De forma constante, as instituições educacionais parecem insistir em criar uma sala de aula cada vez mais desconectada de outras esferas da vida das pessoas e carrega para os AVAs essa característica.

Entretanto, não é nosso intuito julgar a postura da escola, mas alertar e refletir sobre as potencialidades das novas tecnologias, as quais podem auxiliar e contribuir para que novos processos de ensino sejam inseridos no ambiente escolar, modificando a sala de aula e aproximando-a do mundo e do contexto em que nossos alunos estão inseridos. Borba et al., (2014, p. 94) realçam que "as redes sociais podem ainda ser usadas por professores e estudantes em combinação com softwares como o GeoGebra e outras mídias".

Nesse sentido, por compreender e acreditar que as redes sociais podem ser benéficas para os processos de ensino e aprendizagem da Matemática, utilizamo-nos das ideias de Rosa e Shirley (2016, p. 1, tradução nossa): "O campo da etnomatemática estuda diversas formas de conhecimento e aprendizagem, bem como o conhecimento culturalmente embutido na ação pedagógica deste programa dos alunos"17. Ao discutirem o papel da Etnomatemática na sociedade e nas instituições de ensino, os autores ainda relatam que a "Etnomatemática explora a interação de formas acadêmicas e culturais para fornecer programas de desenvolvimento inclusivos para diversas populações servidas pelas instituições de ensino" 18 (ROSA; SHIRLEY, 2016, p. 1, tradução nossa). A leitura desses excertos fez com que nos posicionássemos favoráveis à utilização, inserção e integração das redes sociais, por meio dos celulares inteligentes, nos ambientes de ensino.

Após o envio do questionário e o recebimento das respostas dos vinte e seis alunos que se propuseram a respondê-lo, coletamos e analisamos, em conjunto, os dados, além de fazermos algumas reflexões acerca dos resultados. Como professores e pesquisadores, assumimos o papel de mediadores, permitindo que os discentes tivessem 'voz' e desenvolvessem, dessa forma, o espírito matemático-investigativo.

Pelos resultados, a turma do Nono Ano pôde conferir e afirmar que os celulares inteligentes faziam parte da vida dos alunos da escola investigada havia alguns anos e que a grande parte deles conseguiu seu primeiro aparelho entre os nove e doze anos de idade. $\mathrm{O}$ tempo que a maioria passava acessando seus smartphones - mais de oito horas diárias -

\footnotetext{
${ }^{17}$ Original: "The field of ethnomathematics studies students' diverse ways of knowing and learning as well as culturally embedded knowledge in the pedagogical action of this program".

${ }^{18}$ Original: "Ethnomathematics explores the interaction of academic and cultural ways to provide inclusive developmental programs for diverse populations served by educational institutions".
} 
causou forte impacto. Tais fatos sustentam que as redes sociais não representavam uma novidade para os adolescentes em questão.

Contudo, o resultado que gerou maior polêmica foi o considerável número de trocas dos citados aparelhos eletrônicos, bem como o destino 'final' que lhes era reservado ao serem descartados/inutilizados. Dos vinte e seis entrevistados, vinte e quatro responderam que já haviam substituído, no mínimo, duas vezes seus celulares. O fato chamou a atenção da turma, pois o 'trocar de celular' não estava atrelado à permuta entre os indivíduos, mas à aquisição de um novo. Segundo relatos dos discentes, possuir um smartphone demonstrava um certo 'status' entre os colegas e amigos, onde a competição pelo melhor e mais moderno tipo/marca era característica própria dessa geração que não cogitava a possibilidade de ficar sem um smartphone/iphone.

Essa busca pela novidade e valorização, impulsionada pelo capitalismo e a tentativa de melhor compreender o que os alunos pensavam, levaram-nos a perceber que "a valorização do que é novo, mais potente ou, simplesmente, diferente, já faz parte das concepções culturais e sociais presentes na atualidade" (KENSKI, 2014, p. 62). Portanto, 'buscar o novo' tem sido uma das características culturais da sociedade, e sua prática aumentado consideravelmente não apenas no que tange à aquisição de aparelhos digitais, mas às diversas áreas pertencentes ao cotidiano dos indivíduos.

Assim, após meditarem e compreenderem esse aspecto culturalmente imbricado na vida das pessoas, os alunos passaram a refletir sobre o destino dos aparelhos ao serem substituídos. Diante dos dados coletados, aproximadamente, um terço deles acabava no lixo. A percepção do que isso significava em uma sociedade imersa na aquisição e portabilidade de celulares inteligentes gerou comentários como o do aluno K: mas será que a gente pode jogar um celular assim no lixo? Isso é seguro ou não pode prejudicar a natureza?.

\section{Conclusão}

Posto isso, como professores e pesquisadores, pensamos que, diante da imersão da sociedade na utilização dos celulares inteligentes, que denominamos "Etnocelular", proibir o seu uso não é uma solução adequada, principalmente nos processos de ensino e aprendizagem de nossos alunos. Contudo, é preciso (re)educá-los de maneira a levá-los a manusear corretamente essa ferramenta para que ela possa ser integrada à escola. Borba e Lacerda (2015, p. 500, grifos nossos) expressam que "se não queremos o celular nas salas de aula devido a condutas inadequadas dos nossos alunos, precisamos então educá-los de forma a integrar essa tecnologia móvel à cultura escolar e ao material didático dos alunos".

Diante dos resultados, fica explícito que os smartphones conquistaram não apenas o público jovem, mas as demais faixas etárias. Sua utilização, hoje, vai além de uma ligação, 
uma mensagem de texto ou acesso instantâneo à internet. O fato é que cada indivíduo atribui seus significados ao adquirir seu aparelho celular, passando a utilizá-lo da maneira que deseja e que lhe é útil. Ademais, expressa suas razões, significados, anseios e necessidades pelos quais deseja suprir ao portar esse artefato, visando ao auxílio em suas atividades, sejam elas de lazer, profissional e/ou pessoal.

Com inúmeras funções e formas de utilização, os smartphones eram utilizados pelos jovens e adolescentes da referida localidade visando às relações sociais, ao contato pessoal e ao acesso rápido à internet, podendo acessar aplicativos online - redes sociais -, jogos, músicas e outros entretenimentos. Contudo, podemos aferir - ainda que superficialmente que, conforme relatos dos adultos, a utilização dessa ferramenta tem contribuído/facilitado a execução de outras tarefas, como trabalho, comunicação de baixo custo e ainda a facilidade na comunicação de/com pessoas portadoras de necessidades especiais (abordados durante o relato das convidadas).

O fato é que muitas são as razões de esses aparelhos terem se tornado tão comuns, tais como satisfazer e suprir necessidades pessoais, não necessariamente de comunicação, mas de vida. Como mencionado anteriormente, as pessoas têm atribuído significados muito particulares a seus celulares a tal ponto de carregá-los aonde quer que estejam. Conforme o relato dos alunos, nem mesmo na própria escola - onde seu uso era proibido - eles desistiam da ideia de portá-lo. Estavam com 'eles' a todo instante, consequentemente, nunca esquecidos, permitindo-nos, assim, afirmar que as pessoas, hoje, em especial os brasileiros, estão fortemente interligados a essa cultura, reportando-nos às ideias de Borba (2012). Este afirma que as tecnologias digitais podem ser encaradas como parte/extensão do corpo dos seres humanos.

Assim, acreditamos na existência de uma discrepância quanto à utilização dos celulares inteligentes, pois constatamos que tal artefato tecnológico não tinha espaço no ambiente da sala de aula, ao contrário dos demais. Segundo os próprios alunos, não havia práticas vinculadas ao uso de smartphones, sendo restrito o seu manuseio durante o período em que permaneciam na escola. Ou seja, apenas era permitido no 'mundo fora da escola', o que ocorria constantemente.

Posto isso, reafirmamos que novas pesquisas são essenciais em diferentes áreas do conhecimento para que nossos professores, escolas, representantes e governo possam romper com alguns paradigmas e somar forças na busca pela melhoria da qualidade do ensino em nosso país. Reconhecemos também que se fazem necessários muitos avanços quanto às funções e novos aplicativos voltados ao smartphone, contribuindo, dessa forma, para as melhorias da aprendizagem e cotidiano dos indivíduos 


\section{Referências}

BORBA, M C.; MALHEIROS, A. P. dos S.; AMARAL, R, B. Educação a distância online. $3^{\text {a }}$ Ed. Belo Horizonte: Editora Autêntica, 2011

BORBA, M. C. Humans-with-media and continuing education for mathematics teachers in online environments. ZDM, Berlim, v. 44, p. 801-814, 2012.

BORBA, M. C.; SILVA, R. S. R. da; GADANIDIS, G.. Fases das tecnologias digitais em Educação Matemática - Sala de aula e internet em movimento. $1^{\mathrm{a}}$ Ed. Belo Horizonte: Autêntica Editora, 2014.

BORBA, M. C.; LACERDA, H. D. G. Políticas públicas e tecnologias digitais: um celular por aluno. Educação Matemática Pesquisa. São Paulo. Volume 17, n.3 p. 490-507, 2015.

D’AMBRÓSIO, U. Educação Matemática: Da teoria a prática. $23^{\text {a }}$ Ed. Campinas, SP: Papirus, 2012.

D’AMBRÓSIO, U. Etnomatemática - o elo entre as tradições e a modernidade. $5^{\mathrm{a}}$ Ed. Belo Horizonte: Autêntica Editora, 2013.

D'AMBROSIO, U.; D'AMBROSIO, B. S. The role of ethnomathematics in curricular leadership in mathematics education. Journal of Mathematics Education at Teachers College, v. 4, p. 19-25, 2013.

D'AMBROSIO, U. An Overview of the History of Ethnomathematics. In: ROSA, M.; D'AMBROSIO, U.; OREY, Daniel C.; SHIRLEY, L.; ALANGUI, W. V.; PALARES, P.; GAVARETTE, M. E. Current and Future Perspectives of Ethnomathematics as a Program. Springer Open. ISBN 978-3-319-30119-8 ISBN 978-3-319-30120-4 (eBook), 2016.

GERSTBERGER, A.; OLIVEIRA, E. C.; GIONGO, I. M.; QUARTIERI, M. T. Uma prática pedagógica utilizando o aparelho celular nas aulas de matemática em uma turma de ensino médio. Revista Caderno Pedagógico, Lajeado, v. 13, n. 1, 2016.

GERSTBERGER, A. Um olhar Etnomatemático acerca da utilização dos smartphones nos Processos de Ensino de Matemática nos anos finais do Ensino Fundamental. Dissertação Mestrado Profissional em Ensino de Ciências Exatas. Lajeado: Universidade do Vale do Taquari - Univates, 2017.

GIL, A. C. Como elaborar projetos de pesquisa. $4^{\text {a }}$ Ed. São Paulo: Atlas, 2002.

GODOY, A. S.. Introdução à pesquisa qualitativa e suas possibilidades. Revista Administração de Empresas(ERA), São Paulo, v. 35, n. 2, p. 57-63, 1995.

GRASSELI, F. Educação Matemática, Etnomatemática e viticultura: analisando uma prática pedagógica. Dissertação (Mestrado Profissional em Ensino de Ciências Exatas) - Centro Universitário Univates, Lajeado, 2012.

HAMENSCHLAGER, V. L. S. Etnomatemática: uma experiência educacional. São Paulo: Summus, 2001.

IDRIS, Y.; WANG, Q. Affordances of Facebook for learning. International Journal of Continuing Engineering Educational and Life-Long Learning, 2-3, p. 247-255, 2009. 
KENSKI, V. M. Tecnologias e tempo docente. Editora Papirus, Campinas-SP, 2014.

KNIJNIK, G.; WANDERER, F.; GIONGO, I. M.; DUARTE, C. G. Etnomatemática em Movimento. $2^{\mathrm{a}}$ Ed. Belo Horizonte: Autêntica Editora, 2013. (Coleção Tendências em Educação Matemática, 25).

LAKATOS, E. M.; MARCONI, M. A.. Metodologia científica. 4. Ed. São Paulo, Atlas, 2004.

MOREIRA, D. P.; SANTOS, M.. O uso da internet por jovens adultos portugueses de uma escola profissional. Revista Caderno Pedagógico, v. 13, n. 1, 2016.

PERUCHIN, D.; NARDINI, F. Linguagem matemática na rede social facebook: potencialidades pedagógicas. ANAIS: VI JORNADA NACIONAL DE EDUCAÇÃO MATEMÁTICA E XIX JORNADA REGIONAL DE EDUCAÇÃO MATEMÁTICA. Universidade de Passo Fundo, 2016.

PICOLI, F. D. C. Alunos/as surdos/as e processos educativos no âmbito da educação matemática: problematizando relações de exclusão/inclusão. Dissertação (Mestrado Profissional em Ensino de Ciências Exatas) - Centro Universitário Univates, Lajeado, 2010.

ROSA, M.; OREY, D.1 C. A trivium curriculum for mathematics based on literacy, matheracy, and technoracy: an ethnomathematics perspective. ZDM, Berlim, v. 47, n. 4, p. 587-598, 2015.

ROSA, M.; SHIRLEY, L.. Introduction. In: ROSA, M.; D'AMBROSIO, U; OREY, D. C.; SHIRLEY, L.; ALANGUI, W. V.; PALARES, P.; GAVARETTE, M. E. Current and Future Perspectives of Ethnomathematics as a Program. Springer Open. ISBN 978-3-319-30119-8 ISBN 978-3-319-30120-4 (eBook), 2016.

ROSA, M.; OREY, D.l C. State of the Art in Ethnomathematics. In ROSA, M.; D'AMBROSIO, U; OREY, D. C.; SHIRLEY, L.; ALANGUI, W. V.; PALARES, P.; GAVARETTE, M. E.. Current and Future Perspectives of Ethnomathematics as a Program. Springer Open. ISBN 978-3-319-30119-8 ISBN 978-3-319-30120-4 (eBook), 2016.

ZANON, R. Educação Matemática, formas de vida e alunos investigadores: Um estudo na perspectiva da Etnomatemática. Dissertação (Mestrado Profissional em Ensino de Ciências Exatas) - Centro Universitário Univates, Lajeado, 2013.

\section{SOBRE OS AUTORES}

ANDRÉ GERSTBERGER. Graduado em Licenciatura Plena em Matemática pela Universidade do Estado de Mato Grosso (2011). Especialista em Docência para o Ensino Superior pela Faculdade de Sinop (FASIPE) em 2012. É Mestre pelo Programa de Pós Graduação em Ensino de Ciências Exatas do Centro Universitário UNIVATES (2017). Atualmente é doutorando em Educação pela Universidade de Lisboa e doutorando em Ensino pela Universidade do Vale do Taquari. Trabalha como Técnico Administrativo Educacional da Escola Estadual Nossa Senhora do Perpétuo Socorro, concursado pelo Estado de Mato Grosso desde 2011. Atua como professor de Matemática do Ensino Fundamental no Instituto Educacional Superação desde 2016. Também é docente na Universidade de Cuiabá (UNIC), campus de Sinop-MT, ministrando aulas de Raciocínio Lógico e Matemático e Matemática Financeira nos cursos de graduação em Administração e Ciências Contábeis. E-mail: andre_canelavera@hotmail.com . 
IEDA MARIA GIONGO. Possui graduação em Matemática - Licenciatura Plena pela Fundação Universidade Federal do Rio Grande, Especialização em Ensino de Matemática pela Pontifícia Universidade Católica do Rio Grande do Sul, Mestrado e Doutorado em Educação pela Universidade do Vale do Rio dos Sinos. Atualmente é professora titular da Universidade do Vale do Taquari - Univates de Lajeado, RS, vinculada ao Centro de Ciências Exatas e Tecnológicas. Coordena o Grupo de Pesquisa Práticas, Ensino e Currículos (CNPq) e participa do Grupo Interinstitucional de Pesquisa em Educação Matemática e Sociedade (GIPEMS). Também atua, como docente permanente, no Mestrado Profissional em Ensino de Ciências Exatas e Programa de Pós-graduação em Ensino da Instituição, coordenando este último. E-mail: igiongo@univates.br .

Recebido: 26 de maio de 2017.

Revisado: 20 de outubro de 2017.

Revisado: 20 de janeiro de 2018.

Aceito: 08 de fevereiro de 2018. 